\title{
O Significado das Coberturas Terciárias nas Chapadas da Região Centro-Oeste
}

\author{
Lindinalva Mamede \\ Pesquisadora Titular do IBGE/DIGEO-CO e \\ Doutoranda da USP/CAPES. \\ Av. $85 \mathrm{n}^{\circ} 971$ - Setor Sul \\ CEP.: 74.160-011 - Goiânia-Goiás \\ Telefone: (062)225-4700 Fax: (062)225-1684
}

\begin{abstract}
The detritic deposits cover the plateaus and chapadas of the Central West region. They occur in high topografic levels between 700 and $1340 \mathrm{~m}$ high. This terciary coverage has transported sediments associated to pediplain and whish were furthely soil formed by soil processes.
\end{abstract}

Os depósitos detríticos terciários encontramse distribuidos em diversas áreas dos planaltos e chapadas da região Centro-Oeste. Essa sedimentação recobre tanto terrenos paleozoico-mesozóicos, como pré-cambrianos. Ocupam grandes extensões e ocorrem sobre o Planalto dos Parecis, Planaltos Setentrionais da Bacia Sedimentar do Paraná e os Planaltos do Divisor Tocantins-Paraná (Fig. 01).

A cobertura terciária ocorre nos topos dos relevos mais elevados, posionada entre 700 e $1.340 \mathrm{~m}$ de altitude, geralmente capeando níveis topográficos remanescentes de uma superficie aplanada. Caracteriza-se por configurar chapadas ou chapadões de topos aplanados ou suavemente dissecados, constituídos por argilas, areias e siltes, já pedogeneizados, originando predominantemente Latossolos Vermelho-Escuros, os quais se sobrepõem a uma camada de crostas ferruginosas, de espessura variável. Por vezes, abaixo dela, observa-se a existência de um. conglomerado basal composto de arenitos e basaltos.

Os chapadões são revestidos de vegetação de Cerrado ou Campo Sujo e quase sempre são delimitados por ressaltos topográficos de 20 a $40 \mathrm{~m}$, esculpidos nos sedimentos terciários. Em alguns locais, os chapadões que caracterizam o compartimento elevado coalescem com a superficie do compartimento rebaixado. Quando isto ocorre, a cobertura terciária se adelgaça. Nestes casos, geralmente não se observa a presença de crostas, apenas o material alterado e pedogeneizados que origina 0 Latossolo Vermelho-Escuro, mas com grande variação textural. O contato com a superficie do compartimento rebaixado é então assinalado pela diferenciação pedológica. A drenagem que tem suas cabeceiras nesses chapadões, junto aos ressaltos topográficos que os delimitam, geralmente escava anfiteatros por erosão remontante, a qual atua diferencialmente nas crostas ferruginosas da cobertura terciária e nas rochas areníticas subjacentes.

Sobre as formas aplanadas ou suavemente dissecadas dos chapadōes, observam-se feições geomorfológicas locais, de aspecto distinto. Trata-se de microformas associadas à presença de térmitas e de vales do tipo "veredas".

$\mathrm{Na}$ região Centro-Oeste, verificou-se que os termiteiros ocorriam tanto no topo dos planaltos quanto nas superficies mais baixas, como na Planicie do Bananal, cuja altimetria oscila em torno de $200 \mathrm{~m}$. Nessa área, Mamede, Ross e Santos (1981) observaram que os termiteiros ocorriam em interflúvios rebaixados parcialmente inundáveis, recobertos por vegetação de Campo Sujo e por Plintossolo. Verificaram ainda que em outras áreas da planície, onde as águas de inundação permaneciam por mais tempo, o solo era o mesmo Plintossolo, porém a vegetação era campo úmido e não ocorriam os termiteiros. Isto pode indicar que, embora a formação das térmitas independa de posicionamento altimétrico específico, existe certa relação com o nível do lençol freático. Elas se desenvolvem em áreas de hidromorfismo, com curto período de permanência das águas.

Penteado Orellana (1980), estudando a presença de termiteiros nas proximidades de Brasilia, refere-se a fato de igual natureza argumentando que essas microformas se instalam "na zona de contato entre a baixa encosta e a planície aluvial, na faixa menos úmida do que a planície e mais úmida do que a encosta adjacente”. Estas observações mostram que a presença das térmitas está associada a:

- proximidade do lençol freático;

- presença de relevos planos com material pouco permeável (argilas e concreções);

- ocorrência de áreas sujeitas a alagamentos, mas por tempo não muito longo.

A outra feição local que se observa sobre os chapadões capeados pela cobertura terciária refere-se a certos tipos de vale, que apresentam-se, rasos, amplos e de fundo plano, com vertentes suaves, geralmente colonizados por vegetação de buriti, associados ou não com espécies de floresta. Vales desse tipo são denominados de "veredas". 
Esses fatos mostram que os relevos capeados pelos sedimentos terciários têm peculiaridades muito marcantes, o que facilita seu reconhecimento nas imagens de radar e fotos aéreas.

Perfis e cortes analisados permitiram concluir sobre as relações de contato dessa cobertura com as litologias subjacentes, permitindo a atribuição de hipóteses para sua formação.

Embora a espessura da cobertura terciária atinja de 20 a $40 \mathrm{~m}$, isto só é facilmente visivel quando há ressalto topográfico. Quando eles não existem, ocorre uma coalescência da superficie do topo da cobertura, com a superficie da litologia subjacente, o que sugere que ambas foram truncadas por uma superfície de erosão posterior a formaçào da cobeertura.

No Chapadão do Rio Verde ( Fig. 01), a cobertura terciária ocorre muitas vezes no reverso da cuesta ou sobre o topo de chapadóes de topografia muito regular. Diversas áreas desse tipo foram observadas. Em algumas foram coletadas amostras para análises granulométricas e morfoscópicas.

Assim, no reverso da cuesta do Caiapó nas proximidades de Portelândia-GO., a $880 \mathrm{~m}$ de altitude, foi amostrado um perfil de cerca de $3 \mathrm{~m}$ de profundidade, formado por Latossolo VermelhoEscuro. O perfil é extremamente homogêneo, apresentando material bastante argiloso, do qual foi retirada, a 1,10 $\mathrm{m}$ de profundidade, uma amostra para análise de laboratório, com o seguinte resultado:

- na análise granulométrica, verificou-se que o índice de seleção do material é muito probremente selecionado, descartando a possibilidade de ser um depósito lacustre, ou de qualquer outro agente que selecione bem as particulas; $e$

- na análise morfoscópica, constatou-se que mais de $50 \%$ dos grãos de quartzo são subarredondadados a bem arredondados, indicando que o material sofreu transporte, sendo portanto um colúvio; além disso, $80 \%$ dos grãos de quartzo têm brilho vitreo, o que indica transporte em água, e $20 \%$ do material analisado comporta nódulos ferruginosos, dos quais $95 \%$ com brilho, sugerindo que os horizontes pedológicos acima do que foi coletado a amostra são alóctones.

Ainda nas proximidades de Portelândia observou-se que as vertentes que ladeiam a descida para o vale do córrego Água Emendada apresentavam um perfil como o que se segue:

- no topo, $5 \mathrm{~m}$ de material pedogeneizado constituindo Latossolo;

- abaixo, uma camada de disposição sinuosa, com 0,55 m de espessura, composta por concreções ferruginosas muito resistentes; $e$

- sob ela, uma camada de siltitos permianos do Grupo Passa Dois.
Mais para oeste desse local, na serra da Uritiga. a parte pedogeneizada da cobertura terciária tem cerca de $20 \mathrm{~m}$ de espessura. Abaixo dela se observam $3 \mathrm{~m}$ de material concrecionário, assentados sobre arenitos da Formação Botucatu. Os sedimentos terciários formam um ressalto topográfico suavizado pelo recuo da vertente. Notou-se que, à medida que os arenitos vão sendo removidos, a camada concrecionada sobreposta vai desabando lentamente, promovendo a suavização da vertente. Já os arenitos Botucatu originam uma segunda ruptura de declive, porém bastante pronunciada, de aspecto escarpado.

Em chapadão localizado próximo ao limite dos Estados de Mato Grosso do Sul e Goiás, onde se localiza a vila de Taquari, o comportamento dessa cobertura terciária também pôde ser analisado. $O$ topo do referido Chapadão é constituido por espessa camada de Latossolo Vermelho Escuro, do qual foi retirada, a cerca de $1 \mathrm{~m}$ da superficie, uma amostra para análise em laboratório, cujos resultados foram similares aos da amostra anterior:

- indice de seleção das partículas, é de um material muito pobremente selecionado; e

- morfoscopia mostrando $50 \%$ dos grãos de quartzo arredondados a bem arredondados, indicando transporte; $80 \%$ dos grãos de quartzo com brilho vitreo, indicando transporte em água, não se verificando, entretanto, nódulos ferruginosos, como na amostra anterior.

O levantamento pedológico do Projeto RADAMBRASIL classificou o solo dessa área como Latossolo Vermelho-Escuro A moderado, textura muito argilosa (Novaes, et al (1983), cuja descrição morfológica é a seguinte:

Al 0-10cm, bruno-avermelhado (5YR 4/3); muito argiloso; moderada pequena e média granular; ligeiramente duro, friável, muito plástico e muito pegajoso; transição plana e difusa

A3 10-27cm, bruno-avermelhado (5YR 4/4; muito argiloso; moderada média e grande granular, ligeiramente duro, friável, muito plástico e muito pegajoso; transição plana e difusa.

Bl 27-53cm, vermelho (2,5YR 4/6); muito argiloso; fraca muito pequena a pequena granular com aspecto maciça porosa in situ; macio, friável, muito plástico e muito pegajoso; transição plana e difusa.

B21 53-110cm, vermelho (2,5YR 4/6); muito argiloso; fraca muito pequena a pequena granular com aspecto macica porosa in situ; macio, friável, muito plásstico e muito pegajoso; transição plana e difusa. 
$110-170 \mathrm{~cm}$, vermelho $(2,5 \mathrm{YR} 4 / 6) ;$ muito argiloso; fraca muito pequena a pequena granular com aspecto maciça porosa in situ; macio, friável, muito plástico e muito pegajoso.

Esse elenco de informações, permitiu levantar duas hipóteses sobre a natureza desse material:

a) seria resultante de uma sedimentação recente, provavelmente terciária;

b) resultaria de uma alteração in situ, constituindo pois uma unidade edafoestratigráfica.

Diversos pesquisadores já se referiram a esses sedimentos, alguns inclinando-se para a primeira hipótese, outros para a segunda. Contudo, seus trabalhos quase sempre se referiam a seçoos isoladas de ocorrência desse material, sem que houvesse uma preocupação com a comparação e $\mathrm{a}$ análise de todas as áreas de ocorrência.

Durante o levantamento geomorfológico sistemático do Centro-Oeste, realizado pelo Projeto RADAMBRASIL, a distribuição das coberturas terciárias foi sendo gradativamente acompanhada. Mais afeitos ao estudo de sedimentos recentes, os geomorfólogos se preocuparam em estabelecer comparações que lhes permitissem estabelecer diretrizes para o entendimento da origem e natureza do material. Assim Mamede, Ross e Santos (1981), quando do mapeamento da Folha SC.22-Tocantins, admitiram que a sedimentação pliocênica mapeada no quadrante sudoeste da referida Folha estaria relacionada a aplanamentos que elaboraram a superficie do Planalto Dissecado do Sul do Pará. Segundo aqueles autores, o planalto, embora muito dissecado e fragmentado, sugere que formava um grande conjunto de relevos com altitudes decrescentes para sul e sudoeste, coincidindo com a superficie truncada e contrária ao arranjo da drenagem atual. Funcionaria, provavelmente, como área-fonte de sedimentos, durante pelo menos todo o periodo terciário, e como parte de um antigo divisor de água, entre a Região Norte e o Brasil Central. "Tal divisor migrou para sul em função de arqueamentos e processos erosivos, invertendo a drenagem e a posição relativa das áreas-fontes $e$ de deposição de sedimentos", conforme referiram os mesmos autores.

Na Chapada dos Parecis e no Planalto dos Guimarães, os geólogos do Projeto RADAMBRASIL denominaram essa cobertura de Unidade TerciáriaQuaternária detrítico-laterítica(TQdl).

Efetuando o levantamento geomorfológico da Folha SD.22-Goiás, Mamede, Nascimento e Franco (1981) admitiram que os sedimentos terciários recobriam extensivamente os Planaltos dos Parecis e dos Guimarães, compondo uma única superficie, e que em fase posterior teria ocorrido uma tectônica de soerguimento associada a atividade erosiva, abrindo a
Depressão Interplanáltica de Paranatinga, separando os dois planaltos.

Relatam ainda, que a cobertura ocorre sobreposta a diferentes formações geológicas da Bacia Sedimentar do Paraná e pré-cambrianas sempre com um elo de ligação - a presença de espessa camada de alteração já pedogeneizada com características similares, tanto vertical como horizontal. Isto indica que a cobertura tem característica própria e comum, qualquer que seja a litologia subjacente. Por outro lado, as análises granulométricas e morfoscópicas efetuadas indicaram uma origem alóctone de material.

A igual resultado chegou Zebino Amaral Filho (1982), em seu trabalho "Influência da pedologia no mapeamento geológico do Triângulo Mineiro", inédito. Esse autor analisou diversas amostras da cobertura terciária, coletados em trabalhos de campo, e as comparou com os resultados de amostras referentes a solos onde não ocorria essa cobertura. $\mathrm{Na}$ área de solos derivados do Arenito Bauru verificou que o teor de areia é superior a $60 \%$, o de argila inferior a $30 \%$ e o de $\mathrm{Fe}_{2} \mathrm{O}_{3}$ superior ou igual a $12 \%$. Desse modo, considera impossivel que os Arenitos Bauru, Botucatu ou o Basalto Serra Geral tenham originado a cobertura.

Todos esses fatos são indicativos de que o material é alóctone, tendo sido transportado, depositado e então pedogeneizado.

Na descrição de sua seção-tipo, Gonçalves \& Schneider (1970), mostraram intercalações de camadas com variações locais; isto sugere que houve uma sedimentação sobre litologias paleozóicas e mesozóicas. Esses mesmos autores e Pena \& Figueiredo (1972) referem-se à presença de um conglomerado na base da cobertura terciária, o qual associam à deposição fluvial. Por sua vez, Olivatti et al (1980) acreditam que o conglomerado por eles observado na fazenda alto Formoso, constituido de grânulos e seixos angulosos de basalto, corresponde a material de pedimentação, enquanto as camadas que se depositaram sobre ele decorrem de ambiente lacustre. De fato, a área analisada por eles refere-se à chapada do Parque Nacional das Emas. Nela ocorrem vales amplos com largas faixas de inundação (Aai), que parecem exemplificar bem uma drenagem estagnada, possivelmente endorreica, posteriormente reaberta. A discordância erosiva entre as formaçōes Serra Geral, Botucatu e Grupo Bauru não só sugere que é uma deposição como também comprova uma idade posterior à pediplanação que truncou litologias paleozóicas e mesozóicas. Se o Grupo Bauru é tido como Cretáceo Superior, o período erosivo que truncou este grupo só poderia ser, na hipótese mais remota, do Terciário Inferior, e esses sedimentos seriam um depósito correlativo de aplanamentos ocorridos no Terciário. É possivel que estejam ligados a fases de pediplanação compreendidas entre o Mioceno e Plioceno, identificadas em mapeamentos 
anteriores do Projeto RADAMBRASIL, no Planalto Dissecado do Sul do Pará, nos relevos topograficamente elevados do Planalto Central Goiano e até mesmo nos Planaltos da Bacia Sedimentar do Paraná. Esta interpretação é concordante com as idéias de Ab'Saber (1965), quando descreve que a "porção sul-amazônica do Escudo Brasileiro é talvez a única velha plataforma residual que permaneceu um tanto a escapo das grandes deformações modernas, a qual certamente foi afetada por fenômenos de pediplanação extensiva que afetaram o sul da Amazônia dos meados para fins do Terciário. Tratando-se pois, de uma legítima plataforma, a qual não foi muito estimulada pela epirogênese, tendo permanecido na categoria de superficie de degradação lenta por quase todo o Terciário".

Em face de toda essa argumentação, chega-se a conclusões em três niveis:

1) A cobertura terciária compreende sedimentos transportados, não constituindo, pois, uma unidade edafoestratigráfica, in situ;

2) Essa sedimentação está associada a pediplanações terciárias que favoreceram a deposição de detritos sobre parte da Bacia Sedimentar do Paraná e Planaltos do Distrito Federal em condições de semiaridez, tendo sido posteriormente pedogeneizada, mas já em situação climática a duas estações, provocando a latossolização do material e a formação de crostas ferruginosas;

3) A sedimentação teve um caráter extensivo no Centro-Oeste do Brasil, sendo, provavelmente, contemporânea à deposição da Formação Barreiras, muito conhecida na literatura brasileira.

\section{Referências Bibliográficas}

AB'SABER, A.N. Da participação das depressões periféricas e superficies aplainadas na compartimentação do planalto brasileiro. São
Paulo, Universidade de Filosofia, Ciências e Letras, 1965. 178p.

Gonçalves, A \& SCHNEIDER, RL. Geologia do centro-leste de Mato Grosso. Ponta Grossa, PETROBRÁS - DE SUL, 1970. 43p. (Relatório Técnico Interno, 394).

Mamede, L.; Nascimento, M.AL.S do; Franco, M. do S.M. Geomorfologia. In: Projeto RADAMBRASIL. Folha SD.22-Goiás. Rio de Janeiro, 1981. (Levantamento de Recursos Naturais, 25).

Mamede, L. Ross, J.L.S.; Santos L.M. dos Geomorfologia. In: Projeto RADAMBRASIL. Folha SC.22-Tocantins. Rio de Janeiro, 1981. (Levantamento de Recursos Naturais, 22)

Mamede et al. Geomorfologia. In: Projeto RADAMBRASIL. Follha SE.22-Goiânia. Rio de Jaeniro, 1983. (Levantamento de Recursos Naturais, 31)

Novaes et al. Pedologia. In: Projeto RADAMBRASL, Folha SE.22-Goiânia. Rio de Janeiro, 1983. (Levantamento de Recursos Naturais, 31)

Olivatti et al. Projeto Paulipetro, da geologia do bloco 71, relatório final. Goiânia, CPRM/Paulipetro, $1980,61 \mathrm{p}$

Pena, G.S. \& Figueiredo, A.J. de A. Projeto Alcalina; Relatório Final. Goiânia, DNPM/CPRM, 1972.3v. (Relatório de Arquivo Técnico da DGM, 1943) v. 1.

Penteado-Orellana, M.M. Microrrelevos associados a térmitas no cerrado. Notícia Geomorfológica, Campinas, 20(39/40): 61-72, dez. 1980. 

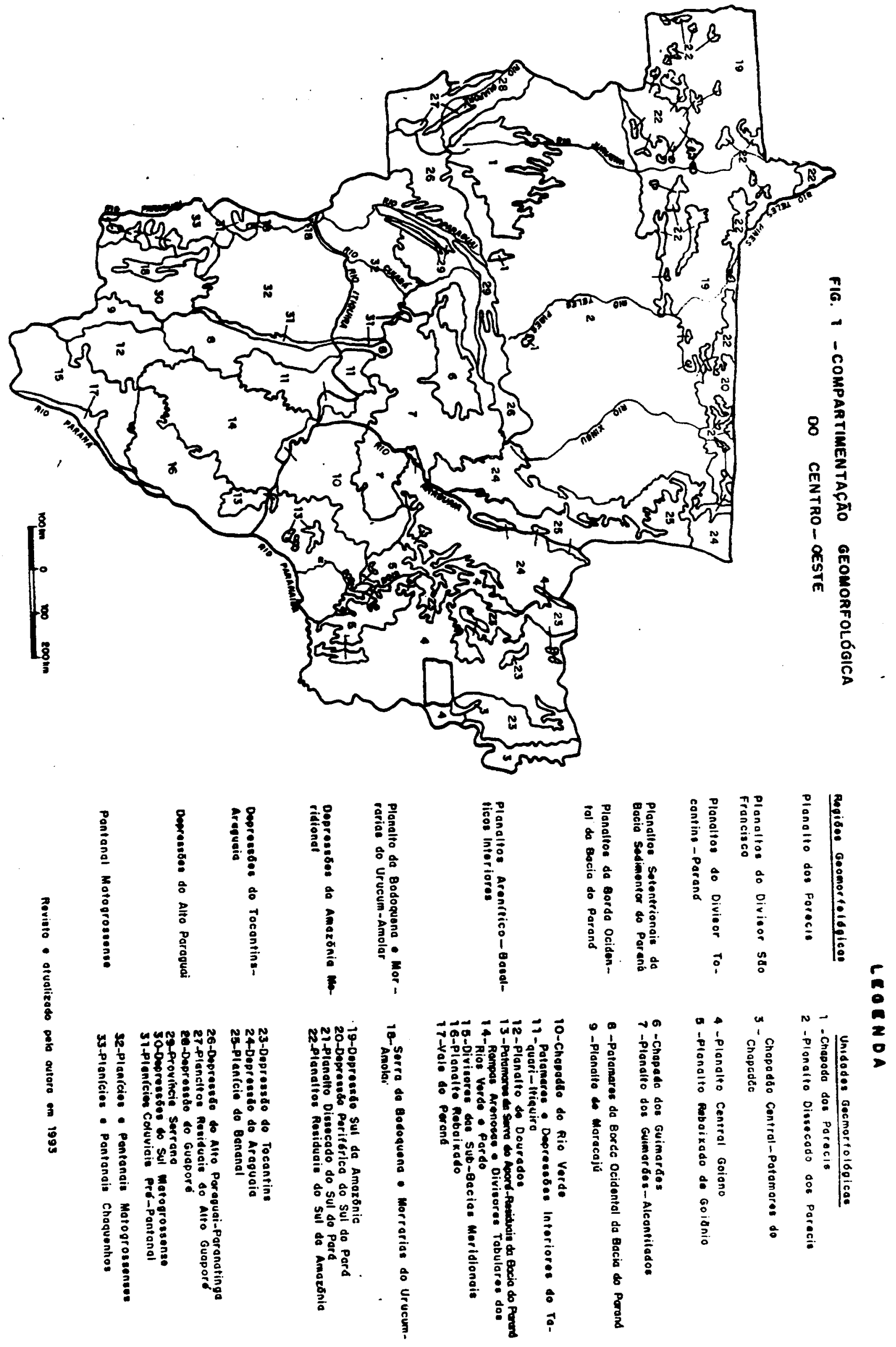